\title{
Exceptionally Steep Brain-Body Evolutionary Allometry Underlies the Unique Encephalization of Osteoglossiformes
}

\author{
Masahito Tsuboi ${ }^{\mathrm{a}, \mathrm{b}}$ \\ ${ }^{a}$ Department of Biology, Lund University, Lund, Sweden; ${ }^{\text {b }}$ Department of Biosciences, University of Oslo, \\ Oslo, Norway
}

\section{Keywords \\ Evolutionary constraints · Static allometry · Mormyrid . \\ Measurement error model $\cdot$ Evolutionary allometry}

\begin{abstract}
Brain-body static allometry, which is the relationship between brain size and body size within species, is thought to reflect developmental and genetic constraints. Existing evidence suggests that the evolution of large brain size without accompanying changes in body size (that is, encephalization) may occur when this constraint is relaxed. Teleost fish species are generally characterized by having close-fitting brain-body static allometries, leading to strong allometric constraints and small relative brain sizes. However, one order of teleost, Osteoglossiformes, underwent extreme encephalization, and its mechanistic bases are unknown. Here, I used a dataset and phylogeny encompassing 859 teleost species to demonstrate that the encephalization of Osteoglossiformes occurred through an increase in the slope of evolutionary (among-species) brain-body allometry. The slope is virtually isometric (1.03 $\pm 0.09 \mathrm{SE})$, making it one of the steepest evolutionary brain-body allometric slopes reported to date, and it deviates significantly from the evolutionary brain-body allometric slopes of other clades of tele-
\end{abstract}

ost. Examination of the relationship between static allometric parameters (intercepts and slopes) and evolutionary allometry revealed that the dramatic steepening of the evolutionary allometric slope in Osteoglossiformes was a combined result of evolution in the slopes and intercepts of static allometry. These results suggest that the evolution of static allometry, which likely has been driven by evolutionary changes in the rate and timing of brain development, has facilitated the unique encephalization of Osteoglossiformes.

(C) 2021 The Author(s)

Published by S. Karger AG, Basel

\section{Introduction}

The close association between brain and body size is one of the most persistent features of the vertebrate body plan [Jerison, 1973; Tsuboi et al., 2018b]. The scaling relationship between brain size and body size is commonly described by power functions in the form of $Y=a X^{b}$, where $\mathrm{Y}$ is brain size, $\mathrm{X}$ is body size, and $b$ is the scaling exponent. This relationship is usually expressed in the logarithmic scale, yielding the standard linear allometric equation: $\log ($ brain size $)=\log (a)+b \log ($ body size $)$. The theoretical context of this equation is that if brain and body sizes are under common growth regulation, then it
(C) 2021 The Author(s)

Published by S. Karger AG, Basel

This is an Open Access article licensed under the Creative Common Attribution-NonCommercial-4.0 International License (CC BY-NC) (http://www.karger.com/Services/OpenAccessLicense), applicable to the online version of the article only. Usage and distribution for commercial purposes requires written permission.
Correspondence to:

Masahito Tsuboi, masa.tsuboi@gmail.com 
approximates a linear relationship between the two traits [Huxley, 1932; Voje et al., 2014]. The slope " $b$ " of this relationship at the within-species level, either across individuals of different developmental stages (ontogenetic allometry) or across adult individuals (static allometry), is of substantial interest to evolutionary biologists because it is considered to characterize the strength and direction of genetic and developmental constraints [Lande, 1979; Riska and Atchley, 1985; Grabowski, 2016; Tsuboi et al., 2018 b]. Brain-body allometry across species, which is referred to as evolutionary allometry, is an emergent property of the slope and the intercept of ontogenetic and static allometry and the covariance of these parameters with body size [Pélabon et al., 2013; Voje et al., 2014]. The universal and close fit of brain-body allometry to observations within and among species has triggered rigorous attempts to understand the causes of brain-body allometry and its consequences for brain size evolution [Dubois, 1897; Lapicque, 1907; Jerison, 1973; Gould, 1975; Martin, 1981; Striedter, 2005; Boddy et al., 2012; Montgomery et al., 2016; Tsuboi et al., 2018b; Mitov et al., 2019; Ksepka et al., 2020; Smaers et al., 2021].

Currently, most phylogenetic comparative studies of brain size focus on explaining the fraction of variation in brain size that is uncorrelated with body size, which is commonly referred to as relative brain size [Jerison, 1973; Gonzalez-Voyer et al., 2009; Liao et al., 2016; DeCasien et al., 2017; Fox et al., 2017; Fristoe et al., 2017; Tsuboi et al., 2017]. These studies regress log-transformed data on brain size against log-transformed data on body size and a set of explanatory variables in a multiple regression, and the partial correlation coefficients of this model are used to test for hypotheses about adaptation and coevolution. The core premise of this framework is that there is variation in relative brain size within a population. However, this assumption may not always be met. In many vertebrate taxa, brain size and body size are closely correlated within populations [Dubois, 1897; Lapicque, 1907; Tsuboi et al., 2016, 2018b; Sukhum et al., 2019], implying that variation in relative brain size (e.g., conditional variance [Hansen and Houle, 2008; Voje et al., 2014]) may often be limited. Birds and mammals are an exception because variational dependence of brain size and body size appears to be decoupled in these taxa, allowing for brain size to respond to selection independently of body size [Boddy et al., 2012; Holekamp et al., 2013; Tsuboi et al., 2018b]. This helps explain the paradox of encephalization under allometric constraints in these lineages, but birds and mammals are not the only lineages with large relative brain sizes.
The fish order Osteoglossiformes, which is also known as boney tongues, is a group of freshwater fish species that inhabit lakes and rivers in Africa, Australia, South Ameri$\mathrm{ca}$, and southern Asia. One family of Osteoglossiformes, Mormyridae, has long been famous for its extremely large relative brain sizes [Nilsson, 1996; Chapman and Hulen, 2001; Kaufman et al., 2003], and it has received considerable attention from neurobiologists [Striedter, 2005]. For instance, in an emblematic species, Gnathonemus petersii, the brain mass constitutes about $3 \%$ of the total body mass, which is extremely large for teleost fishes and even higher than the corresponding value for humans, which is about $2 \%$ [Nilsson, 1996]. More recently, a growing number of reports on brain and body size in other members of Osteoglossiformes revealed that a large relative brain size is not specific to Mormyridae, but it is a characteristic shared by the whole order [Bauchot et al., 1995; Chapman and Hulen, 2001; Sukhum et al., 2016]. To date, studies on the evolution of brain size in Osteoglossiformes have focused exclusively on the ecological causes and physiological consequences of encephalization [Bauchot et al., 1995; Nilsson, 1996; Chapman and Hulen, 2001; Kaufman et al., 2003; Carlson et al., 2011; Sukhum et al., 2016, 2019], and the mechanism Osteoglossiformes have used to reduce allometric constraints is unknown. One hypothesis is that Osteoglossiformes evolved their large brains by reducing the association between brain and body sizes [Tsuboi et al., 2018b]. However, currently available data suggest that this is unlikely. Chapman and Hulen [2001] reported the brainbody static allometric slopes of four species of mormyrids that ranged between 0.36 and 0.63 with $r^{2}$ values of $69 \%$ to $99 \%$. Another three mormyrids examined by Sukhum et al. [2019] revealed static slopes between 0.43 and 0.63 with $r^{2}$ values of $85 \%-98 \%$. These ranges of static allometric slopes and high $r^{2}$ values are typical in teleost fishes [Tsuboi et al., 2016,2018 b], suggesting that the evolutionary path for encephalization in Osteoglossiformes might be fundamentally different from that in birds and mammals.

There are two non-mutually exclusive scenarios for encephalization under strong allometric constraints. First, the intercept of the static allometry could evolve even if brain and body sizes remain closely correlated. An artificial selection experiment in the guppy, Poecilia reticulata, demonstrated that the static brain-body allometric intercept has additive genetic variance and can evolve in response to artificial selection on relative brain size [Kotrschal et al., 2013]. Additionally, the evolution of relative brain size in Lake Tanganyika cichlids is predominantly driven by evolutionary changes in the static allometric intercept [Tsuboi et al., 2016]. Alternatively, rela-
Brain Behav Evol 2021;96:49-63 DOI: $10.1159 / 000519067$
Tsuboi 
tive brain size can evolve through coevolution of the static allometric slope and body size [Pélabon et al., 2013]. A positive association between among-species divergence in relative brain size and the variance of the static allometric slope in boney fish corroborates this hypothesis [Tsuboi et al., 2018b]. In this study, I first document the encephalization of Osteoglossiformes using an updated dataset of brain and body sizes in teleost fishes. Then, I evaluate static brain-body allometry from 103 species, including 17 species of Osteoglossiformes, to determine the mechanistic basis of their unique encephalization.

\section{Materials and Methods}

\section{Data and Phylogeny}

I combined a recently curated dataset of vertebrate brain and body masses [Tsuboi et al., 2018a] with brain and body mass data for Osteoglossiformes reported in Sukhum et al. [2016]. Bauchot et al. [1995] was consulted but not included in this study because they only reported juvenile individuals. My primary dataset consisted of brain mass (g) and body mass (g) of 3,632 adult individuals from 859 species, including 21 species of Osteoglossiformes and 838 species of other teleost fishes. A phylogeny including all of the 859 species was obtained from Rabosky et al. [2018] and used to conduct phylogenetic comparative analyses. Additionally, despite their unknown phylogenetic positions, 19 species of Osteoglossiformes (online suppl. Data S1; for all online suppl. material, see www.karger.com/doi/10.1159/000519067) were included in a subset of my analyses to increase the sample size of this clade. Brainbody static allometries were estimated by fitting ordinary leastsquares regressions of the natural log of brain mass against the natural log of body mass for all species with 10 or more observations available. The static allometric intercept of the untransformed data is often considered a parameter of little biological significance due to the inherent negative association between slopes and intercepts [White and Gould, 1965], and mean-centering is recommended before estimating the static allometric intercepts to dissociate the relationship [Voje et al., 2014]. However, the static allometric intercepts and slopes were weakly correlated for the data compiled in this study $\left(r^{2}=2.0 \%\right.$, online suppl. Fig. S1). Additionally, among animals that exhibit indeterminate growth, the static allometric slope is typically constant over a wide size range [Tsuboi et al., 2018b]. Empirical data of fish ontogenetic brainbody allometry suggest that the initially near-isometric slope shifts to species-specific static allometry at $0.03-3.00 \mathrm{~g}$ of body mass [Bauchot et al., 1979; Oikawa and Itazawa, 1984; Oikawa et al., 1992]. This suggests that the static allometric intercept, which is the predicted brain mass at $1 \mathrm{~g}$ of body mass [Halley, 2016], roughly corresponds to the brain mass at which static allometry starts. Assuming that this ontogenetic model generally applies to teleosts, I used the static allometric intercept in the natural logarithm of uncentered data in my analyses.

Comparative Framework

I modeled trait evolution on a phylogenetic tree based on an Ornstein-Uhlenbeck (OU) model. I first evaluated the phylogenetic signal of each trait, including log brain mass, log body mass, brain-body static allometric slope, and intercept, by estimating the phylogenetic half-life $\left(t_{1 / 2}\right)$ of an OU process [Hansen, 1997]. $t_{1 / 2}$ describes the tendency of traits to evolve toward an adaptive optimum $(\theta)$, which is the phylogenetic weighted mean when OU is fitted to a single trait. The unit of $t_{1 / 2}$ is the tree length (millions of years), allowing an intuitive interpretation of the phylogenetic signal. Additionally, the stationary variance $\left(v_{\mathrm{st}}\right)$ characterizes the variance of a fitted trait when they evolve under a constant adaptive regime for a long time.

Evolutionary correlations between variables were assessed using a generalized least-squares regression model in which the residual variance structure was modeled based on an OU process [Hansen et al., 2008]. As brain mass, body mass, static allometric slope, and static allometric intercept are hypothesized to be connected through development, I used a direct-effect model that considers that the evolution of predictors has an immediate effect on the response [Grabowski et al., 2016]. This model has the following form:

$$
d y=-a(y-\theta) d t+b d x+\sigma d W,
$$

where dy is the change in trait y over an infinitesimal time step dt, $\alpha$ is the strength of pull toward $\theta$, which characterizes the model intercept, $\sigma \mathrm{dW}$ describes a white noise with independent, normally distributed random changes with a mean of zero and variance $\sigma^{2}$, and the parameter $b$ describes the scales of change in log brain mass with the change in predictor variables, $\mathrm{dx}$, which follows an independent white-noise process. This model converges to the phylogenetic generalized least squares with residual structure modeled as Brownian motion (BM) as the a parameter asymptotes toward zero. Based on this model, I estimated the evolutionary brain-body allometry of eight orders represented by 20 or more species: Anguiformes $(n=20)$, Beryciformes $(n=21)$, Gadiformes $(n=35)$, Osteoglossiformes $(n=21)$, Perciformes $(n=576)$, Scorpaeniformes $(n=34)$, Syngnathiformes $(n=22)$, and Tetraodontiformes $(n=35)$, as well as all species $(n=859)$ except for one of the eight examined orders. In the dataset of Beryciformes, Anoplogaster cornuta was a clear outlier (online suppl. Fig. S2). Previous studies of brain size in marine fishes have shown that the transition from mesopelagic to bathypelagic habitat is associated with a significant decrease in brain size [Fine et al., 1987; Kotrschal et al., 1998; Iglesias et al., 2015], which likely reflects the lower levels of ambient light and energy sources in bathypelagic zones than mesopelagic zones [Kotrschal et al., 1998]. In the presented data, $A$. cornuta was the only bathypelagic species within Beryciformes and had a small relative brain size. Considering these observations as indications that the brain size of $A$. cornuta is evolving under a selective regime that is distinct from other members of Beryciformes in the data, I removed A. cornuta from the analysis of Beryciformes.

Using a subset of data of estimated static allometric slopes (hereafter referred to as static data, $n=87$ species), I fitted four models. The first model was an allometry-only model in which the $\log$ of brain mass was regressed against the log of body mass. The log of body mass was included as a covariate in all other models. In the second model, I regressed the log of brain mass against the static allometric slope. In the third model, the log of brain mass was regressed against the static allometric intercept, and the fourth model regressed the log of brain mass against the static allometric slope and intercept. Model fit was evaluated based on the sample 


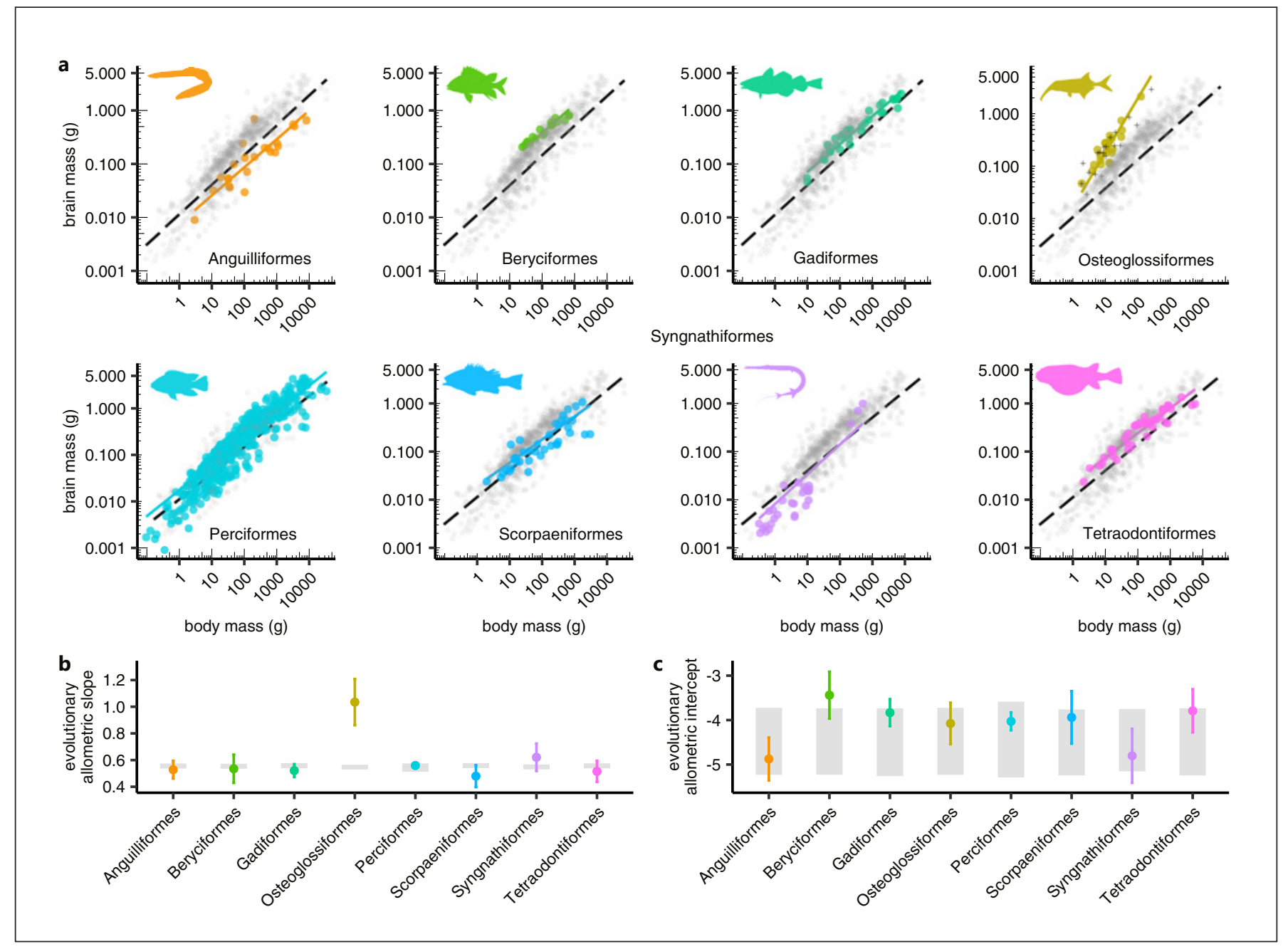

Fig. 1. Comparison of evolutionary allometry among teleost fish species. a Relationships between brain mass ( $\mathrm{g}$ ) and body mass ( $\mathrm{g}$ ) are presented. Eight orders with sufficient sample sizes are highlighted in each panel. Colored circles represent mean values of species belonging to one of the eight orders and gray circles indicate the rest. Colored solid lines show evolutionary allometry of each order, and black dashed lines show evolutionary allometry of all taxa except for the compared order (estimates are shown in online suppl. Table S1). Crosses (+) represent Osteoglossiformes whose data were available but not included in SLOUCH analyses due to the lack of phylogenetic information $(n=21$ species are included

size-corrected Akaike Information Criterion (AICc) and the model $r^{2}$. A full model with a nested model without a focal predictor was compared to assess the effect of each predictor on relative brain mass. I repeated the analyses using the subset of data for Osteoglossiformes. Due to the limited sample size in this clade, I included all species with at least two observations $(n=17)$. This caused some estimates of the static allometric slopes to be unreliable. The reliability of static allometric slopes and intercepts was accounted for by including measurement variances of the estimates in the comparative analyses to allow robust statistical infer- in the analyses and $n=40$ are plotted). Note that $\log _{10}$ scales are only used for graphical representation, while all analyses were conducted using natural logarithms. Silhouettes were obtained from phylopic.org. See Supplementary Material for individual image credits. b Comparison of evolutionary allometric slopes across eight orders of teleost. c Comparison of evolutionary allometric intercepts across eight orders of teleost. b, $\mathbf{c}$ Error bars indicate \pm 2 standard errors, and thick gray bars indicate ranges of estimates \pm 2 standard errors for evolutionary allometries including all taxa except for the focal order.

ence. I used SLOUCH version 2.1.2 [Kopperud, 2017] to perform phylogenetic comparative analyses.

\section{Modeling Measurement Variance}

Currently, most comparative studies are based on species means. When species means are imprecise or the total variance is low relative to the imprecision of species means, the imprecision in species means must be modeled to obtain unbiased estimates of regression parameters [Riska, 1991; Ives et al., 2007; Hansen and Bartoszek, 2012]. Measurement imprecisions can be evaluated in 
Table 1. Evolutionary brain-body allometry estimated by direct-effect SLOUCH model in 8 orders of Teleost

\begin{tabular}{|c|c|c|c|c|c|c|c|}
\hline Order & $t_{1 / 2}$ & $v_{\mathrm{st}}$ & Intercept \pm SE & Slope \pm SE & $r^{2}$ & $\begin{array}{l}p \text { value } \\
\text { (intercept) }\end{array}$ & $\begin{array}{l}p \text { value } \\
\text { (slope) }\end{array}$ \\
\hline Anguilliformes & $-^{*}$ & $0^{*}$ & $\begin{array}{l}-4.876 \pm 0.241 \\
(-4.694 \pm 0.253)\end{array}$ & $\begin{array}{l}0.528 \pm 0.033 \\
(0.502 \pm 0.035)\end{array}$ & $90.0 \%$ & 0.53 & 0.51 \\
\hline Beryciformes $^{\dagger}$ & $-^{*}$ & $0^{*}$ & $\begin{array}{l}-3.439 \pm 0.263 \\
(-2.838 \pm 0.339)\end{array}$ & $\begin{array}{l}0.535 \pm 0.053 \\
(0.409 \pm 0.069)\end{array}$ & $92.3 \%$ & 0.10 & 0.77 \\
\hline Osteoglossiformes & $0.128[0.000-\infty]$ & $0.072[0.022-\infty]$ & $\begin{array}{l}-4.077 \pm 0.233 \\
(-3.610 \pm 0.277)\end{array}$ & $\begin{array}{l}1.034 \pm 0.087 \\
(0.819 \pm 0.110)\end{array}$ & $80.3 \%$ & 0.46 & $<0.001$ \\
\hline Perciformes & $\infty[7.020-\infty]$ & - & $\begin{array}{l}-4.029 \pm 0.100 \\
(-0.390 \pm 0.102)\end{array}$ & $\begin{array}{l}0.560 \pm 0.011 \\
(0.527 \pm 0.012)\end{array}$ & $86.4 \%$ & 0.45 & 0.55 \\
\hline Tetraodontiformes & $\infty[0.313-\infty]$ & - & $\begin{array}{l}-3.792 \pm 0.243 \\
(-3.438 \pm 0.270)\end{array}$ & $\begin{array}{l}0.516 \pm 0.039 \\
(0.450 \pm 0.045)\end{array}$ & $88.5 \%$ & 0.26 & 0.40 \\
\hline
\end{tabular}

Phylogenetic half-life $\left(t_{1 / 2}\right.$, unit: total tree height) and stationary variance $\left(v_{s t}\right)$ are shown with 2 maximum-likelihood support range from the maximum likelihood estimate in squared brackets. Estimates within parentheses indicate parameters estimated without correcting for measurement errors. Asterisk $\left(^{*}\right)$ indicates that the model had no residual variance $\left(v_{s t}=0\right)$ after measurement errors are accounted for, in which case $t_{1 / 2}$ is not estimable. Dagger $\left(^{\dagger}\right)$ indicates that Anoplogaster cornuta was excluded from the analysis. The $p$ values represent tests against the null hypothesis that presented estimates are the same as estimates of overall evolutionary allometry for all teleost excluding the order to be compared (estimates are shown in online suppl. Table S1).

the form of measurement variance $\left(\sigma^{2} \mathrm{~m}\right)$, which is calculated as the squared standard error of the species means. However, this approach cannot be used when species are represented by a single observation, and it provides an unreliable estimate of the true $\sigma^{2 \mathrm{~m}}$ when the sample size is low. Therefore, I used a method developed by Grabowski et al. [2016], which models the sample variance $\left(s^{2}\right)$ as the weighted sum of the species-specific $s^{2}\left(s^{2}{ }_{i}\right)$ and the global $s^{2}$ $\left(s_{\text {global }}^{2}\right)$. The weighting is determined by the fraction of variation in the $s^{2}$ due to true among-species difference in $s^{2}$ i over the imprecision of $s^{2}$ itself [see Appendix A of Grabowski et al., 2016]. I iteratively fitted SLOUCH with $s^{2}{ }_{i}$ as a response variable in an intercept-only model in which $t_{1 / 2}$ was set to zero (i.e., phylogeny is not considered) to estimate $s^{2}$ global and variance in $s^{2}$. In the first iteration, the measurement variance of $s^{2}{ }_{i}$ was modeled as $s^{4}{ }_{\mathrm{i}} /\left(n_{\mathrm{i}}-1\right)$, where $n_{\mathrm{i}}$ was the sample size of the species. In subsequent iterations, the measurement variance of $s^{2}{ }_{i}$ was modeled as the square of the estimated mean of $s^{2}$ in the previous iteration divided by $\left(n_{\mathrm{i}}-1\right)$. This procedure was repeated until estimates converged, and the converged $v_{\text {st }}$ and mean were obtained as the estimate of variance in $s^{2}$ and estimate of $s^{2}$ global, respectively. I applied this procedure for the log of body mass, log of brain mass, static allometric slopes, and static allometric intercepts, and I used the formula provided in Grabowski et al. [2016] to model $\sigma^{2 \mathrm{~m}}$ in these traits for each species. The estimated measurement variances were included in all statistical analyses performed using R version 3.6.0 [R Core Team, 2019].

\section{Results}

An updated dataset of teleost brain mass and body mass showed an evident deviation of Osteoglossiformes from general teleost brain-body evolutionary allometry (Fig. 1). Visual inspection of evolutionary allometry in eight orders of teleost indicated that evolutionary brainbody allometry in teleost orders is remarkably conserved in terms of both slope and intercept, except for Osteoglossiformes, which clearly showed a steeper evolutionary allometry than the other seven teleost orders (Fig. 1a). A closer examination of the evolutionary allometric slope confirmed that only Osteoglossiformes deviate significantly from the evolutionary allometric slope of all but the focal order (Fig. 1b, $p<0.001$; Table 1; online suppl. Table S1) with the allometric relationship of $\log$ (brain mass $)=1.03 \times \log ($ body mass $)-4.08$. In contrast, I found no evidence that the intercepts of evolutionary allometry in any of the eight examined orders deviated from the intercepts estimated for the rest of the data (Fig. 1c; Table 1; online suppl. Table S1). These results provide strong 
Table 2. Phylogenetic half-life $\left(t_{1 / 2}\right)$, stationary variance $\left(v_{\text {st }}\right)$, and optimum $(\theta)$ of an OU process fitted to four examined traits in the entire static data and in three subsets of the data

\begin{tabular}{lllr}
\hline Trait & $t_{1 / 2}$ & $v_{\text {st }}$ & $\theta \pm S E$ \\
\hline Full static data, $n=87$ & & & \\
Log (brain mass) & $0.552[0.279-5.046]$ & $2.467[1.546-17.638]$ & $-2.014 \pm 0.503$ \\
Log (body mass) & $0.296[0.164-0.800]$ & $4.744[3.212-9.929]$ & $3.791 \pm 0.548$ \\
Static slope & $0.120[0.007-0.566]$ & $0.005[0.003-0.010]$ & $0.457 \pm 0.014$ \\
Static intercept & $\infty[0.657-\infty]$ & - & $-3.641 \pm 0.330$ \\
\hline Perciformes, $n=57$ & & & $-1.864 \pm 0.404$ \\
Log (brain mass) & $\infty[0.637-\infty]$ & - & $3.989 \pm 0.571$ \\
Log (body mass) & $\infty[0.345-\infty]$ & - & $0.461 \pm 0.017$ \\
Static slope & $0.200[0.025-\infty]$ & $0.005[0.002-\infty]$ & $-3.713 \pm 0.152$ \\
Static intercept & $1.621[0.253-\infty]$ & $0.420[0.130-\infty]$ & $-4.772 \pm 0.212$ \\
\hline Syngnathiformes, $n=12$ & & & $1.236 \pm 0.356$ \\
Log (brain mass) & $0[0-0.094]$ & $0.533[0.259-1.390]$ & $0.430 \pm 0.046$ \\
Log (body mass) & $0[0-0.081]$ & $1.500[0.727-3.863]$ & $-5.376 \pm 0.118$ \\
Static slope & $0.098[0.051-\infty]$ & $0.012[0.002-\infty]$ & \\
Static intercept & $0.018[0.051-\infty]$ & $0.103[0.030-\infty]$ & $-1.579 \pm 0.272$ \\
\hline Osteoglossiformes, $n=17$ & & & $2.440 \pm 0.233$ \\
Log (brain mass) & $0.095[0-\infty]$ & $0.768[0.424-\infty]$ & $0.520 \pm 0.045$ \\
Log (body mass) & $0.100[0-\infty]$ & $0.734[0.363-\infty]$ & $-2.991 \pm 0.119$ \\
Static slope & $0.010[0.051-\infty]$ & $0.014[0.004-\infty]$ & \\
Static intercept & - & $0 *$ & \\
\hline
\end{tabular}

Phylogenetic half-life $\left(t_{1 / 2}\right.$, unit: total tree height) and stationary variance $\left(v_{\mathrm{st}}\right)$ are shown with 2 maximum-likelihood support range from the maximum likelihood estimate in squared brackets. Asterisk $\left(^{*}\right)$ indicates that the model had no residual variance $\left(v_{s t}=0\right)$ after measurement errors are accounted for, in which case $t_{1 / 2}$ is not estimable.

Fig. 2. Comparison of static allometric parameters. Osteoglossiformes (yellow), Perciformes (blue), and Syngnathiformes (purple) are compared. Solid circles represent the central state of an Ornstein-Uhlenbeck process $(\theta)$ fitted to static slopes and intercepts and shown with \pm 2 standard errors (estimates are shown in Table 2). Open circles are observations.

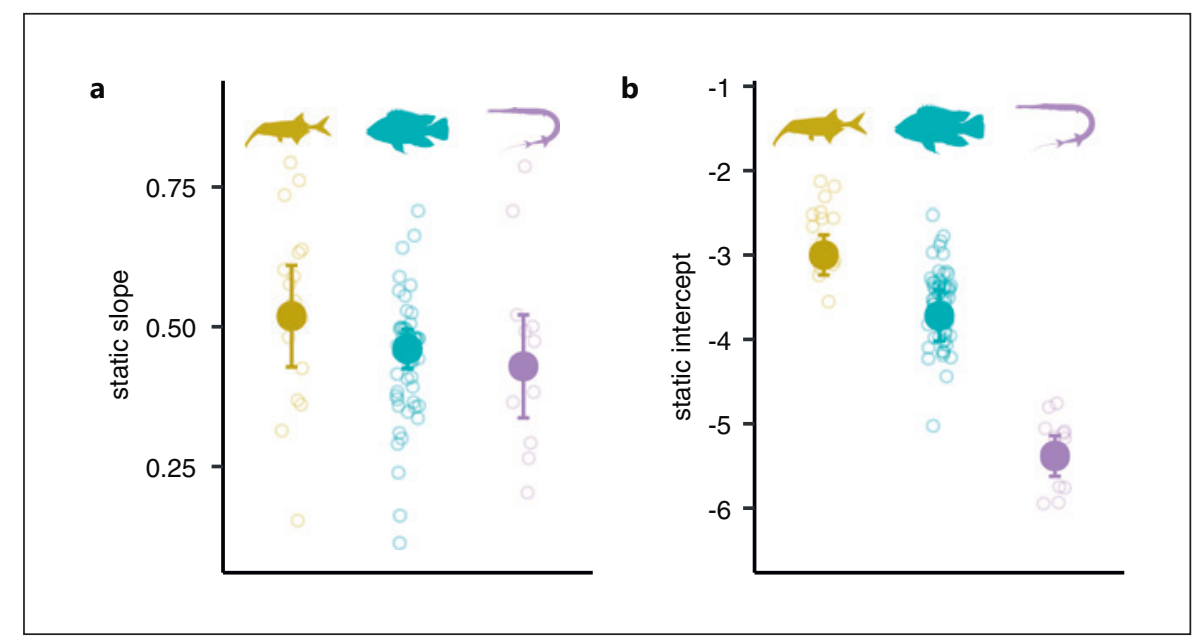

evidence that the exceptional encephalization of Osteoglossiformes predominantly occurred through evolutionary change in the slope of evolutionary allometry. Regarding these findings as validation for a single scaling relationship across non-osteoglossomorph teleosts, I evaluated the brain mass of Osteoglossiformes relative to expected values based on the evolutionary brain-body allometry of $\log$ (brain mass $)=0.55 \times \log$ (body mass $)-$ 
Table 3. Phylogenetic associations among brain mass, body mass, static slope, and static intercept

\begin{tabular}{|c|c|c|c|c|c|c|c|}
\hline Response & Predictor & $t_{1 / 2}$ & $v_{s t}$ & Intercept $(\theta)$ & Slope & $r^{2}$ & $\mathrm{AICC}$ \\
\hline \multicolumn{8}{|l|}{ Perciformes, $n=57$} \\
\hline Log (brain mass) & $\log$ (body mass) & $\infty(0.991-\infty)$ & - & $-4.019 \pm 0.194$ & $0.536 \pm 0.031$ & $83.1 \%$ & 10.3 \\
\hline Log (brain mass) & $\begin{array}{l}\text { log (body mass) } \\
+ \text { static slope }\end{array}$ & $\infty(0.867-\infty)$ & - & $-4.331 \pm 0.211$ & $\begin{array}{l}0.544 \pm 0.032 \\
0.604 \pm 0.113\end{array}$ & $83.4 \%$ & 11.9 \\
\hline Log (brain mass) & $\begin{array}{l}\text { log (body mass) } \\
+ \text { static intercept }\end{array}$ & $0.441(0-\infty)$ & - & $-2.304 \pm 0.310$ & $\begin{array}{l}0.496 \pm 0.035 \\
0.421 \pm 0.049\end{array}$ & $85.2 \%$ & 6.0 \\
\hline \multicolumn{8}{|c|}{ Syngnathiformes, $n=12$} \\
\hline Log (brain mass) & $\log$ (body mass) & $\infty(1.242-\infty)$ & $0.131(0.061-\infty)$ & $-5.429 \pm 0.162$ & $0.559 \pm 0.061$ & $87.1 \%$ & 22.1 \\
\hline Log (brain mass) & $\begin{array}{l}\text { log (body mass) } \\
+ \text { static slope }\end{array}$ & $\infty(0-\infty)$ & - & $-6.431 \pm 0.166$ & $\begin{array}{l}0.595 \pm 0.059 \\
2.346 \pm 0.141\end{array}$ & $90.5 \%$ & 24.2 \\
\hline \multicolumn{8}{|c|}{ Osteoglossiformes, $n=17$} \\
\hline Log (brain mass) & $\log$ (body mass) & $0.121(0-\infty)$ & $0.085(0.035-\infty)$ & $-3.956 \pm 0.257$ & $0.989 \pm 0.097$ & $82.2 \%$ & 27.3 \\
\hline Log (brain mass) & $\begin{array}{l}\text { log (body mass) } \\
\text { + static slope }\end{array}$ & $0.105(0-\infty)$ & $0.041(0-\infty)$ & $-5.356 \pm 0.299$ & $\begin{array}{l}0.911 \pm 0.090 \\
3.099 \pm 0.290\end{array}$ & $87.6 \%$ & 27.0 \\
\hline Log (brain mass) & $\begin{array}{l}\text { log (body mass) } \\
+ \text { static intercept }\end{array}$ & $0.118(0-\infty)$ & $0.058(0.008-\infty)$ & $10.546 \pm 0.248$ & $\begin{array}{l}0.652 \pm 0.096 \\
4.839 \pm 0.014\end{array}$ & $83.1 \%$ & 29.8 \\
\hline Log (brain mass) & $\begin{array}{l}\text { log (body mass) } \\
+ \text { static intercept } \\
+ \text { static slope }\end{array}$ & - & $0^{*}$ & $-1.411 \pm 0.510$ & $\begin{array}{l}0.555 \pm 0.062 \\
0.935 \pm 0.149 \\
2.160 \pm 0.299\end{array}$ & $96.2 \%$ & 11.9 \\
\hline
\end{tabular}

Phylogenetic half-life $\left(t_{1 / 2}\right.$, unit: total tree height) and stationary variance $\left(v_{\mathrm{st}}\right)$ are presented with lower-upper 2 maximum-likelihood units support interval and intercept $(\theta)$ and slope are presented with standard errors. Stationary variance $\left(v_{\mathrm{st}}\right)$ is not shown in models where the best estimates of phylogenetic half-lives are infinity because stationary phases are never reached in such cases. Asterisk $\left(^{*}\right)$ denotes that the model had no residual variance after measurement error was accounted for. $t_{1 / 2}$ is not estimable in this case.

4.52, and I found that species of Osteoglossiformes have on average $566 \% \pm 43 \%$ (SE, $n=40$ ) heavier brain masses than typical teleost fish species with similar body masses.

As preliminary analyses using the static data revealed that the relationships between static allometry and brain size were order specific, I primarily report results from three orders represented by 10 or more species (Osteoglossiformes, $n=17$; Perciformes, $n=57$; Syngnathiformes, $n=12$ ). Comparing static allometric slopes and intercepts across these three orders revealed substantial variation in static allometric parameters (Fig. 2). Generally, Osteoglossiformes were found to be evolving toward steeper slopes ( $\mathrm{OU}$ central state, $\theta \pm \mathrm{SE}=0.52 \pm 0.05$ ) and higher intercepts $(-2.99 \pm 0.12)$ than Perciformes (slope: $0.46 \pm 0.01$, intercept: $-3.61 \pm 0.33$ ), while Syngnathiformes were found to be evolving toward shallower slopes

Resolving the Puzzle of Encephalization in Osteoglossiformes
$(0.43 \pm 0.05)$ and lower intercepts $(-5.38 \pm 0.12)$ than Perciformes (Table 2). In a hypothetical fish with a body mass of $1 \mathrm{~g}$, intercept estimates indicate that Osteoglossiformes are predicted to have a brain mass $(0.050 \mathrm{~g})$ that is twice as large as in Perciformes $(0.026 \mathrm{~g})$ and 10 times as large as in Syngnathiformes (0.0046 g). In the complete static data, the four examined traits showed moderate to long $t_{1 / 2}(0.120-\infty$; Table 2$)$. Notably, even a relatively short $t_{1 / 2}$ of 0.120 (lower-upper 2 ML units support intervals: $0.007-0.566)$ for static allometric slope corresponds to 23.1 (1.9-109.9) millions of years (myr) given the total tree height of 192.8 myr. The $t_{1 / 2}$ of the static intercept was infinity $(0.657-\infty)$, meaning that the model converges to $\mathrm{BM}$. BM is a model in which divergence of a trait is proportional to the length of branches of a phylogeny that are not shared among species. Therefore, 
Fig. 3. Relationship between relative brain size and brain-body static allometric slopes and intercepts. The relationship is plotted within Perciformes (a, b), Syngnathiformes $(\mathbf{c}, \mathbf{d})$, and Osteoglossiformes $(\mathbf{e}, \mathbf{f})$. Relative brain sizes are residuals of a directeffect SLOUCH model of $\log$ (brain mass) against $\log$ (body mass) in each of the three datasets. Note that these residuals are only used for visualization purposes. Dashed lines are ordinary least-squares regressions. $r^{2}$ values were evaluated as the proportional increase in a model $r^{2}$ with the focal predictor relative to a reduced model (details of model parameters are presented in Table 3). Error bars indicate standard errors.

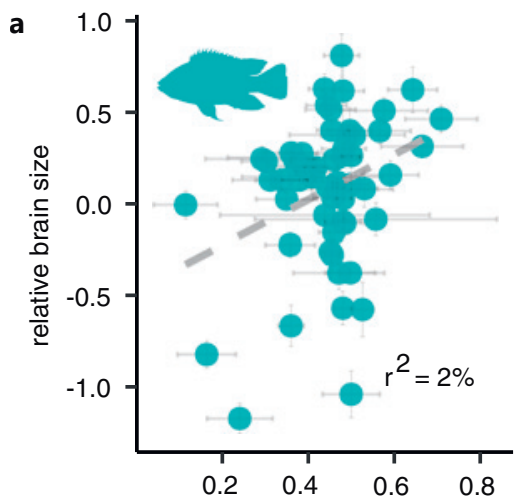

b

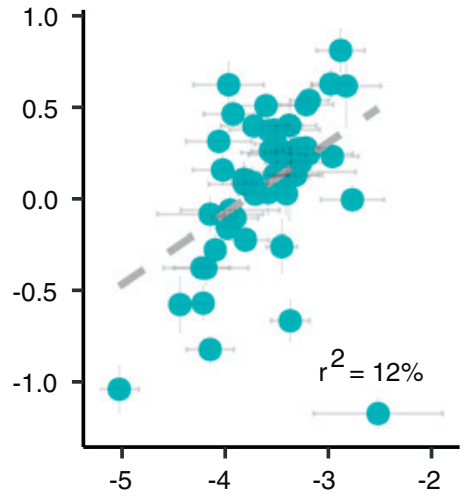

c

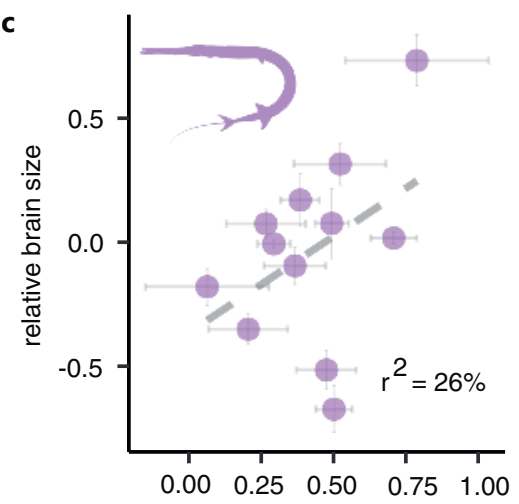

d
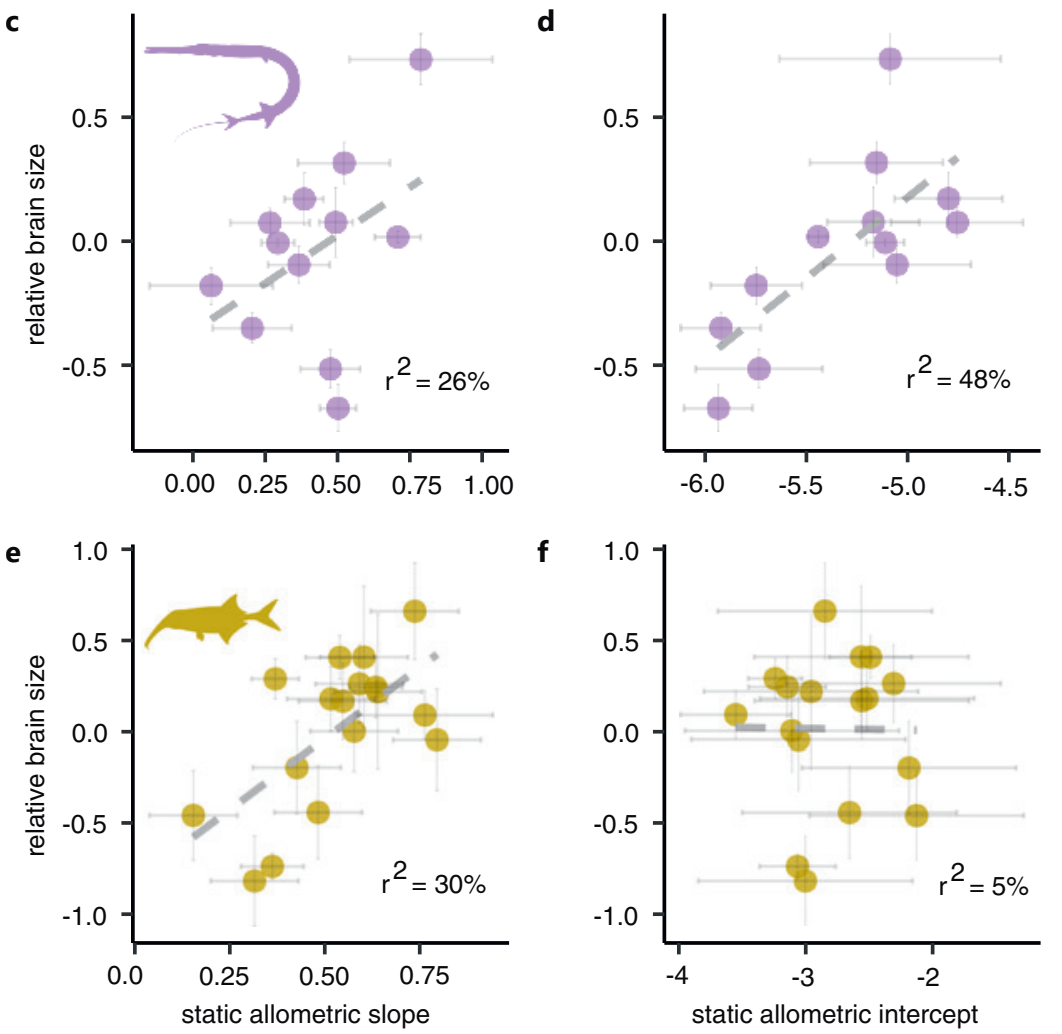

f

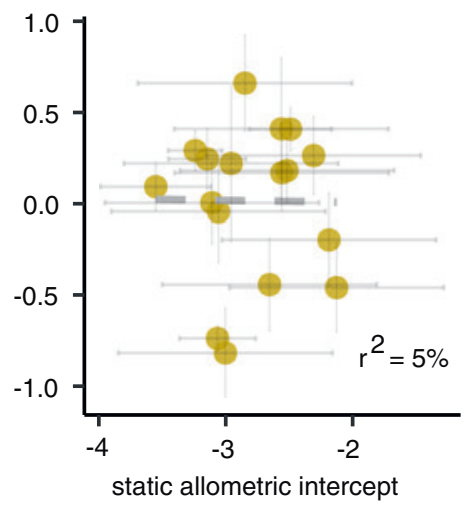

the BM fit suggests that the evolution of static intercepts is strongly influenced by shared ancestry. Taken together, although static allometric parameters varied considerably among taxa, their evolution was relatively slow and left substantial room for the static allometry to constrain the direction of brain size evolution over short time scales.

Parameter estimates of the direct-effect OU regressions are presented in Table 3. Static allometric slopes were positively correlated with relative brain size in spe- cies of Osteoglossiformes $\left(r^{2}=30 \%\right.$; Fig. 3) and Syngnathiformes $\left(r^{2}=26 \%\right)$. The effect of static slope on relative brain size was weak in Perciformes $\left(r^{2}=4 \%\right)$, but there was a positive trend. This finding could be due to a lack of statistical power as the static slope of Perciformes showed considerably lower variance than the other two orders (stationary variance of fitted OU processes [lower-upper $2 \mathrm{ML}$ units support intervals]; Perciformes: $0.005[0.002-\infty]$, Osteoglossiformes: 0.014 [0.004- $\infty$, 


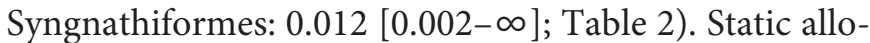
metric intercepts were correlated with relative brain size in Perciformes $\left(r^{2}=12 \%\right)$ and Syngnathiformes $\left(r^{2}=\right.$ $48 \%)$ but not in Osteoglossiformes $\left(r^{2}=5 \%\right)$. This finding indicates that both intercepts and slopes are related to relative brain size in fish species, but their relative contributions vary among orders. In Osteoglossiformes, the inclusion of a static intercept in the model resulted in a dramatic drop in the evolutionary allometry (slope \pm SE $=$ $0.65 \pm 0.10)$. Decomposition of the effect of static intercept, static slope, and their interaction on evolutionary allometric slope resulted in 52, 9, and 18\% increases in evolutionary allometric slope, respectively. Notably, despite variation in static allometry in the other two examined orders, there was only a minor increase in the slope of evolutionary allometry for Perciformes (21\%) and Syngnathiformes (20\%). This finding demonstrates that the evolution of static allometry does not necessarily alter evolutionary allometry. These results are all qualitatively equivalent using complete static data (online suppl. Table S2).

\section{Discussion}

Explaining the evolution of relative brain size is challenging when allometric constraints are strong. The fish order Osteoglossiformes has long been known for its large relative brain sizes [Nilsson, 1996; Chapman and Hulen, 2001; Kaufman et al., 2003]. However, available data suggest close brain-body static allometry in this clade [Chapman and Hulen, 2001; Sukhum et al., 2019] (online suppl. Table S3). Here, I confirmed a case of exceptional encephalization in Osteoglossiformes using an updated database and a statistical method accounting for measurement errors. Additionally, I demonstrated that the unique encephalization in this order results from evolutionary change in the slope of evolutionary brain-body allometry. I showed that the slope is virtually isometric $(1.03 \pm 0.09 \mathrm{SE})$, making it the steepest brain-body evolutionary allometry reported to date [Tsuboi et al., 2018b; Ksepka et al., 2020] along with hominins that appear to exhibit a similarly steep evolutionary allometry [1.10 \pm 0.16; Smaers et al., 2021]. Furthermore, the dramatic steepening of the evolutionary allometric slope was a combined result of evolution in the slopes and intercepts of static allometry. In teleosts, the static allometric slopes could reflect the rate of brain growth relative to body growth during the adult stage, while static allometric intercepts could approximate brain mass at the transition

Resolving the Puzzle of Encephalization in Osteoglossiformes between embryonic and juvenile growth phases [Bauchot et al., 1979; Oikawa and Itazawa, 1984; Oikawa et al., 1992]. Therefore, my findings suggest that the evolution of static allometry, which may have been driven by evolutionary changes in the timing of transition between embryonic and juvenile stages and the rate of brain development during the juvenile phase, altered the slope of evolutionary brain-body allometry and facilitated the unique encephalization of Osteoglossiformes.

The slope of evolutionary allometry in Osteoglossiformes was sharply distinct from all the other teleost orders examined in this study. I interpret this as suggesting that species of Osteoglossiformes are evolving under a unique adaptive landscape [Simpson, 1944; Hansen, 1997; Uyeda et al., 2017] that is not shared by other teleost species. An important question to address is whether this shift reflects changes in the pattern of constraints or selective regimes. Based on the partial correlation coefficients of phylogenetic regression models, the isometric evolutionary allometry of Osteoglossiformes was explained $52 \%$ by the static intercept, $9 \%$ by the static slope, and $18 \%$ by the interaction between the static slope and static intercept. Therefore, the steepness of the evolutionary allometric slope has primarily resulted from the evolution of static allometric intercepts. Theoretical work on the relationship between static and evolutionary allometry showed that the static allometric intercept could result in a steep evolutionary allometry when the static intercept is positively correlated with body size [Pélabon et al., 2013; Voje et al., 2014]. This prediction was supported by data in this study (online suppl. Fig. S3), suggesting that the coevolution of body size and static allometric intercept may have played a major role in encephalization of Osteoglossiformes. Furthermore, the static allometric intercepts of Osteoglossiformes were substantially larger than those of other orders of teleosts, strengthening the hypothesis that the evolution of static allometric intercepts could underlie the exceptional encephalization in this clade. The present study corroborates previous findings that the evolution of relative brain size is primarily mediated by evolution in the static allometric intercepts in the guppy [Kotrschal et al., 2013], cichlids [Tsuboi et al., 2016], and sunfishes [Axelrod et al., 2021]. More generally, static allometric intercepts are more variable than static allometric slopes in a variety of traits and taxa [Egset et al., 2012; Voje et al., 2014; Bolstad et al., 2015]. Taken together, the encephalization of Osteoglossiformes appears to have occurred under strong allometric constraints similar to those in other systems, providing limited support for the hypothesis that changes in the pat- 
tern of allometric constraints underlies the encephalization of Osteoglossiformes.

An alternative hypothesis is that the brain-body evolutionary allometry of Osteoglossiformes manifests a unique adaptive scaling relationship. Notably, the family Mormyridae, which is the most species-rich clade within Osteoglossiformes, uses its electroreception and active electrolocation ability for foraging, which allows these fishes to detect food efficiently in turbid and murky waters [Von der Emde and Bleckmann, 1998]. It might be possible that the efficient food intake improves metabolic turnover, which enables mormyrid fishes to evolve exceptionally large brains, which are energetically costly to develop and maintain [Nilsson, 1996]. Furthermore, adaptation to oxygen-deficient environments, which is extremely important in protecting brains from hypoxia damage, has been reported for several mormyrid fishes in the form of an enlarged gill surface area [Chapman and Hulen, 2001], increased hemoglobin content in the blood [Fish, 1956], aquatic surface respiration [Chapman and Chapman, 1998], and decreased metabolic rate [Chapman and Chapman, 1998]. These physiological and behavioral adaptations in mormyrids, and possibly Osteoglossiformes in general, could be the foundation of the adaptive brain-body scaling relationships that are dramatically different from other teleost clades.

There was a modest effect of the static allometric slope on the shift in the evolutionary allometric slope of Osteoglossiformes, and relative brain size (i.e., the deviation of brain size from evolutionary allometry) was positively correlated with the static slope in this clade. Together with the finding that the static slopes of Osteoglossiformes were on average slightly steeper than those of other orders of teleost, these results suggest that the evolution of steep static allometric slopes have contributed to the encephalization of Osteoglossiformes. Although brain size evolution driven by the reduction of allometric constraints and the steepening of static allometric slope are equally plausible scenarios toward encephalization, the latter path seems to be exceedingly rare. Based on currently available data, Osteoglossiformes, Aves, and Mammalia are three clades that represent the apex of the vertebrate brain-body morphospace, and Osteoglossiformes is the only clade of the three in which encephalization appears to be partly driven by the steepening of the static allometric slope. Why is it so uncommon? One explanation is the pleiotropic constraint [Houle et al., 2019]. Due to its high metabolic cost [Nilsson, 1996; Sukhum et al., 2016], enlargement of the brain is often accompanied by evolutionary changes in traits that are tightly linked to energy budgets of organisms, such as fecundity [Kotrschal et al., 2013], egg size [Tsuboi et al., 2015, 2017], or the size of other metabolically expensive organs [Kotrschal et al., 2013; Tsuboi et al., 2015]. It may be plausible that the static allometric slope manifests physiological links among energetically expensive traits, and makes the static slope evolutionarily stable because stabilizing selection in any of the correlated traits would reduce its evolvability. Another concept for consideration is the evolutionary burden [Riedl, 1977]. In mammals, the cerebellum, which is a region of the brain that is most conspicuously expanded in Osteoglossiformes [Bauchot et al., 1995; Nilsson, 1996; Sukhum et al., 2018], develops earlier than the telencephalon [Workman et al., 2013], which is the brain region that is enlarged in birds [Rehkämper et al., 1991] and mammals [Stephan et al., 1981]. If the mammalian model of neurodevelopmental timing is applicable in fish, the evolution of the cerebellum requires changes in the gene regulatory network earlier than those of the telencephalon, and this might be the key event leading to the evolution of, rather than the reduction of, allometric constraints. However, modification in early developmental pathways may influence many other traits. Therefore, it is a "burden" and difficult to realize.

Throughout this study, parameters of static brainbody allometries (intercept and slope) were considered to reflect the rate and timing of neurogenesis, which are poorly understood in teleost fishes. Therefore, an important step toward understanding the developmental and genetic bases of allometric constraints is to elucidate how the simple power function, which is currently used widely in studies of brain size, reflects real neurodevelopmental processes. Available data on the ontogenetic allometry of hatchling to adult stages in teleost fishes [Bauchot et al., 1979; Oikawa and Itazawa, 1984; Brandstätter and Kotrschal, 1989; Oikawa et al., 1992; Tomoda and Uematsu, 1996] suggest that fish brains generally undergo a biphasic mode of growth. The first phase roughly corresponds to the larval period when allometric slopes are close to isometry [Brandstätter and Kotrschal, 1989; Toyoda and Uematsu, 1994]. The rate of brain growth is then slowed down at the onset of the juvenile period, resulting in a shallow allometric slope that continues through the adult stage [Tsuboi et al., 2018b]. Generally, the standard allometric equation fits the data well within each of the two growth phases, suggesting that the exponent of the power function (the allometric slope) may approximate the rate of brain growth in fish species. However, the selection of statistical models should not be determined by statistical fit alone [Smith, 2009; Houle et al.,
58

Brain Behav Evol 2021;96:49-63 DOI: $10.1159 / 000519067$
Tsuboi 
2011; Glazier, 2021]. It needs to be augmented by empirical knowledge of the developmental processes that model parameters are supposed to describe. Further research is required to explore alternative models of allometry [Packard, 2009; Echavarria-Heras et al., 2020] in conjunction with additional empirical knowledge of brain development in fish to construct a model of allometry that is biologically more realistic than the standard model of allometry.

The timing of neurodevelopmental events in teleost species is currently only described in a handful of model species [Ishikawa, 1997; Wullimann and Puelles, 1999]. While a comparative study of brain development across fishes requires more empirical work, it is important to begin testing hypotheses about the consequences of evolutionary changes in the timing of development on brain size evolution. One possible approach is to use life history traits as proxies for the timing of key developmental events. For example, life history traits that are associated with the level of parental investment have been shown to predict relative brain size in birds [Iwaniuk and Nelson, 2003; Isler and van Schaik, 2006] and mammals [Sacher and Staffeldt, 1974; Barton and Capellini, 2011]. Recently, similar patterns have been found in fish, where egg size [Tsuboi et al., 2015, 2017], mode of reproduction [Mull et al., 2011, 2020], or duration of parental care [Tsuboi et al., 2015] were correlated with relative brain size. Based on the aforementioned biphasic model of teleost brain development, it could be hypothesized that these life history traits covary with the timing of the transition between the embryonic and juvenile growth phases so that higher parental investment prolongs the larval growth phase, leading to increased relative brain sizes at adult stages. Testing this idea requires more knowledge of brain development in fishes. Based on the results presented in this paper, obtaining such data in Osteoglossiformes [Haugedé-Carré et al., 1977; Radmilovich et al., 2016] and linking it to data on static allometric slopes and intercepts would be particularly relevant to further advance our understanding of the mechanism of allometric constraints.

In contrast to my findings, Sukhum et al. [2016] reported an evolutionary brain-body allometric slope of 0.79 for 21 species of Osteoglossiformes. The discrepancy between their estimate and mine (1.03) arises primarily from measurement error, as my estimate becomes 0.82 $( \pm 0.11 \mathrm{SE})$ if measurement errors are not controlled for (Table 1). The necessity of accounting for measurement errors in phylogenetic comparative studies is repeatedly debated [Ives et al., 2007; Garamszegi and Møller, 2010; Hansen, 2014], and methods that account for measure-

Resolving the Puzzle of Encephalization in Osteoglossiformes ment errors are regularly implemented [Beaulieu et al., 2012; Hansen and Bartoszek, 2012; Pennell et al., 2014; Uyeda and Harmon, 2014; Mitov et al., 2019]. However, the correction of measurement error is not currently standard practice in phylogenetic comparative studies. It has often been argued that measurement error tends to be small compared to the overall effect that comparative studies seek to explore and that the correction will have negligible effect on statistical inferences [Harmon and Losos, 2005]. This was shown to be the case in several subsets of the presented analyses, with the effect of correction on estimates of the slope ranging from 3\% to $31 \%$ (Table 1). In contrast, Grabowski et al. [2016] reported that the effect of measurement error on brain-body evolutionary allometric slope in 161 primate species is only $0.2 \%$. This example suggests that the effect of measurement errors is data specific, and it is likely to be more conspicuous in lineages with indeterminate growth than lineages with determinate growth due to the wide adult body size range in lineages with indeterminate growth. Therefore, in future studies, the isometric evolutionary brain-body allometry of Osteoglossiformes should be compared with estimates corrected for measurement errors. For example, Smaers et al. [2021] recently reported a steep evolutionary brain-body allometric slope in hominins $(1.10 \pm 0.16 \mathrm{SE})$ using a method that does not account for measurement errors. As hominins and Osteoglossiformes are two of the most extreme cases of encephalization in vertebrates, steep evolutionary allometries in these clades may represent an interesting case of convergence associated with exceptional encephalization. These examples illustrate the value of using a measurement error model and prompt its use in phylogenetic comparative studies [Silvestro et al., 2015].

Although my analyses indicated that the evolution of the static brain-body allometric slope is relatively slow and that brain size evolution in fish is largely likely to occur in the direction of static allometric slopes, these results do not exclude the possibility that the organization of brain regions can change freely. Available data suggest that the encephalization of Osteoglossiformes has been driven primarily by the enlargement of the cerebellum [Bauchot et al., 1995; Nilsson, 1996; Sukhum et al., 2018]. Therefore, it could be possible that selection to increase brain size in Osteoglossiformes may have acted specifically on the size of the cerebellum. This leads to the question of whether the observed steepening of static and evolutionary allometry in the relationship between whole brain mass and body mass could reflect changes in the allometry of cerebellum size. Sukhum et al. [2018] studied 
the allometry of cerebellum volume in relation to total brain volume in 10 species of Osteoglossiformes and showed that the variation in cerebellum volume relative to total brain volume among species is predominantly driven by differences in the intercept of cerebellum-whole brain allometry [online suppl. Table S1 in Sukhum et al., 2018]. More broadly, the scaling relationship (i.e., slope) between brain region size and whole brain size is highly conserved across vertebrates [Yopak et al., 2010]. Therefore, selection to re-structure brain organization may typically act on the intercept of brain region allometry, which is similar to the pattern in the brain-body static allometry suggested in this and previous studies [Kotrschal et al., 2013; Tsuboi et al., 2016].

The present study leaves us with unanswered questions regarding the mechanism that allowed Osteoglossiformes to evolve steep brain-body static and evolutionary allometric slopes, which seems to be extremely rare among vertebrates. Although there is limited information available on the natural history of Osteoglossiformes and conclusive suggestions are difficult to make, I propose four hypotheses that could be worth exploring in the future. First, the encephalization of Osteoglossiformes occurred through the expansion of the cerebellum, which is a brain region that develops relatively early in mammalian neurogenesis [Workman et al., 2013]. A comparison of early neurogenesis between Osteoglossiformes [Haugedé-Carré et al., 1977; Radmilovich et al., 2016] and other teleost fishes [Oikawa and Itazawa, 1984; Brandstätter and Kotrschal, 1990; Oikawa et al., 1992; Toyoda and Uematsu, 1994; Ishikawa, 1997; Maeyama and Nakayasu, 2000; Sylvester et al., 2010] could allow us to identify the developmental and genetic mechanisms underlying the evolutionary changes in static and evolutionary allometric slopes. Second, similar to birds and mammals, the evolution of static allometric intercepts and slopes in Osteoglossiformes might have been channeled through enhanced parental investment [Iwaniuk and Nelson, 2003; Barton and Capellini, 2011; Tsuboi et al., 2018b]. Available data of life history traits in Osteoglossiformes [Okedi, 1970; Kirschbaum and Schugardt, 2002; Nguyen et al., 2017] suggest that the Arowana family Osteoglossidae has particularly advanced parental investment in the form of mouth brooding [Scott and Fuller, 1976; Merrick and Green, 1982; Verba et al., 2014], feeding of juveniles with skin secretion [Lüling, 1964], and extremely large eggs [Yue et al., 2020]. Therefore, it would be interesting to investigate how parental investments and relative brain sizes are related in Osteoglossiformes. Third, as there is good evidence for unique physiological adaptations in mormyrid fishes to cope with oxygen-deficient environments [Fish, 1956; Nilsson, 1996; Chapman and Chapman, 1998; Chapman and Hulen, 2001], examinations of these characteristics in other members of Osteoglossiformes could allow us to test adaptive hypotheses concerning their unique brainbody scaling exponent. Finally, selection could act on traits that are more directly relevant for brain function than overall brain mass, such as the number, distribution, and density of neurons [Marhounová et al., 2019], and these traits may determine the uniqueness of brain size evolution in Osteoglossiformes. Elucidating these and other unforeseen alternative hypotheses explaining the mechanistic basis of the evolutionary change of static and evolutionary allometric slope in Osteoglossiformes could shed light on the role of allometric constraints in vertebrate brain size evolution.

\section{Acknowledgment}

I thank the Center for Advanced Studies at the Norwegian Academy of Science and Letters to host discussions for this work. I thank two anonymous reviewers for providing comments that substantially improved the clarity of this study.

\section{Statement of Ethics}

This study is based completely on published resources and thus no ethical permissions are necessary.

\section{Conflict of Interest Statement}

The author has no conflicts of interest to declare.

\section{Funding Sources}

This work was supported by the Swedish Research Council (Vetenskapsrådet) grant number 2016-06635.

\section{Author Contributions}

M.T. conceived the idea of this paper, assembled and analyzed the data, and wrote the paper.
Tsuboi 


\section{References}

Axelrod CJ, Laberge F, Robinson BW. Interspecific and intraspecific comparisons reveal the importance of evolutionary context in sunfish brain form divergence. J Evol Biol. 2021 Apr;34(4):639-52.

Barton RA, Capellini I. Maternal investment, life histories, and the costs of brain growth in mammals. Proc Natl Acad Sci USA. 2011 Apr;108(15):6169-74.

Bauchot R, Diagne M, Delfini C, Ridet JM. Encephalization and brain organization of the fishes of the family Osteoglossidae. J Hirnforsch. 1995;36(1):143-51.

Bauchot R, Diagne M, Ribet JM. Post-hatching growth and allometry of the teleost brain. J Hirnforsch. 1979;20(1):29-34.

Beaulieu JM, Jhwueng DC, Boettiger C, O’Meara BC. Modeling stabilizing selection: expanding the Ornstein-Uhlenbeck model of adaptive evolution. Evolution. 2012 Aug;66(8):2369-83.

Boddy AM, McGowen MR, Sherwood CC, Grossman LI, Goodman M, Wildman DE. Comparative analysis of encephalization in mammals reveals relaxed constraints on anthropoid primate and cetacean brain scaling. J Evol Biol. 2012 May;25(5):981-94.

Bolstad GH, Cassara JA, Márquez E, Hansen TF, van der Linde K, Houle D, et al. Complex constraints on allometry revealed by artificial selection on the wing of Drosophila melanogaster. Proc Natl Acad Sci USA. 2015 Oct;112(43):13284-9.

Brandstätter R, Kotrschal K. Brain growth patterns in four European cyprinid fish species (Cyprinidae, Teleostei): roach (Rutilus rutilus), bream (Abramis brama), common carp (Cyprinus carpio) and sabre carp (Pelecus cultratus). Brain Behav Evol. 1990;35(4):195211.

Brandstätter R, Kotrschal K. Life history of roach, Rutilus rutilus (Cyprinidae, Teleostei). A qualitative and quantitative study on the development of sensory brain areas. Brain Behav Evol. 1989;34(1):35-42.

Carlson BA, Hasan SM, Hollmann M, Miller DB, Harmon LJ, Arnegard ME. Brain evolution triggers increased diversification of electric fishes. Science. 2011 Apr;332(6029):583-6.

Chapman LJ, Chapman CA. Hypoxia tolerance of the mormyrid Petrocephalus catostoma: implications for persistence in swamp refugia. Copeia. 1998;1998(3):762-8.

Chapman LJ, Hulen KG. Implications of hypoxia for the brain size and gill morphometry of mormyrid fishes. J Zool (Lond). 2001;254(4):461-72.

DeCasien AR, Williams SA, Higham JP. Primate brain size is predicted by diet but not sociality. Nat Ecol Evol. 2017 Mar;1(5):112.

Dubois E. Sur le rapport du poids de l'encéphale avec la grandeur du corps chez les mammifères. Bull Mem Soc Anthropol Paris. 1897;8(1):337-76.
Echavarria-Heras HA, Castro-Rodriguez JR, Leal-Ramirez C, Villa-Diharce E. Assessment of a Takagi-Sugeno-Kang fuzzy model assembly for examination of polyphasic loglinear allometry. PeerJ. 2020 Jan;8:e8173.

Egset CK, Hansen TF, LE Rouzic A, Bolstad GH, Rosenqvist G, Pélabon C. Artificial selection on allometry: change in elevation but not slope. J Evol Biol. 2012 May;25(5):938-48.

Fine ML, Horn MH, Cox B. Acanthonus armatus, a deep-sea teleost fish with a minute brain and large ears. Proc R Soc Lond B. 1987 Mar;230(1259):257-65.

Fish GR. Some aspects of the respiration of six species of fish from Uganda. J Exp Biol. 1956;33(1):186-95.

Fox KC, Muthukrishna M, Shultz S. The social and cultural roots of whale and dolphin brains. Nat Ecol Evol. 2017 Nov;1(11):1699705.

Fristoe TS, Iwaniuk AN, Botero CA. Big brains stabilize populations and facilitate colonization of variable habitats in birds. Nat Ecol Evol. 2017 Nov;1(11):1706-15

Garamszegi LZ, Møller AP. Effects of sample size and intraspecific variation in phylogenetic comparative studies: a meta-analytic review. Biol Rev Camb Philos Soc. 2010 Nov;85(4):797-805.

Glazier DS. Biological scaling analyses are more than statistical line fitting. J Exp Biol. 2021 Jun;224(11):jeb241059. https://doi. org/10.1242/jeb.241059.

Gonzalez-Voyer A, Winberg S, Kolm N. Social fishes and single mothers: brain evolution in African cichlids. Proc Biol Sci. 2009 Jan;276(1654):161-7.

Gould SJ. Allometry in primates, with emphasis on scaling and the evolution of the brain. Contrib Primatol. 1975;5:244-92.

Grabowski M, Voje KL, Hansen TF. Evolutionary modeling and correcting for observation error support a 3/5 brain-body allometry for primates. J Hum Evol. 2016 May;94:106-16.

Grabowski M. Bigger brains led to bigger bodies?: the correlated evolution of human brain and body size. Curr Anthropol. 2016;57(2):17496.

Halley AC. Prenatal brain-body allometry in mammals. Brain Behav Evol. 2016;88(1):1424.

Hansen TF, Bartoszek K. Interpreting the evolutionary regression: the interplay between observational and biological errors in phylogenetic comparative studies. Syst Biol. 2012 May;61(3):413-25.

Hansen TF, Houle D. Measuring and comparing evolvability and constraint in multivariate characters. J Evol Biol. 2008 Sep;21(5):120119.

Hansen TF, Pienaar J, Orzack SH. A comparative method for studying adaptation to a randomly evolving environment. Evolution. 2008 Aug;62(8):1965-77.
Hansen TF. Stabilizing selection and the comparative analysis of adaptation. Evolution. 1997 Oct;51(5):1341-51.

Hansen TF. Use and misuse of comparative methods in the study of adaptation. In: Garamszegi LZ, editor. Modern phylogenetic comparative methods and their application in evolutionary biology: Concepts and practice. Berlin, Heidelberg: Springer; 2014. pp. 35179.

Harmon LJ, Losos JB. The effect of intraspecific sample size on type I and type II error rates in comparative studies. Evolution. 2005 Dec;59(12):2705-10.

Haugedé-Carré F, Kirschbaum F, Szabo T. On the development of the gigantocerebellum in the mormyrid fish Pollimyrus (Marcusenius) Isidori. Neurosci Lett. 1977 Nov;6(2-3):20913.

Holekamp KE, Swanson EM, Van Meter PE. Developmental constraints on behavioural flexibility. Philos Trans R Soc Lond B Biol Sci. 2013 Apr;368(1618):20120350.

Houle D, Jones LT, Fortune R, Sztepanacz JL. Why does allometry evolve so slowly? Integr Comp Biol. 2019 Nov;59(5):1429-40.

Houle D, Pélabon C, Wagner GP, Hansen TF. Measurement and meaning in biology. Q Rev Biol. 2011 Mar;86(1):3-34.

Huxley JS. Problems of relative growth. Essex: Methuen and Company Limited; 1932.

Iglesias TL, Dornburg A, Brandley MC, Alfaro ME, Warren DL. Life in the unthinking depths: energetic constraints on encephalization in marine fishes. J Evol Biol. 2015 May;28(5):1080-90.

Ishikawa Y. Embryonic development of the medaka brain. Fish Biol J Medaka. 1997;9:17-31.

Isler K, van Schaik C. Costs of encephalization: the energy trade-off hypothesis tested on birds. J Hum Evol. 2006 Sep;51(3):228-43.

Ives AR, Midford PE, Garland T Jr. Within-species variation and measurement error in phylogenetic comparative methods. Syst Biol. 2007 Apr;56(2):252-70.

Iwaniuk AN, Nelson JE. Developmental differences are correlated with relative brain size in birds: A comparative analysis. Can J Zool. 2003;81(12):1913-28.

Jerison HJ. Evolution of the brain and intelligence. New York: Academic Press; 1973.

Kaufman JA, Marcel Hladik C, Pasquet P. On the expensive-tissue hypothesis: independent support from highly encephalized fish. Curr Anthropol. 2003;44(5):705-7.

Kirschbaum F, Schugardt C. Reproductive strategies and developmental aspects in mormyrid and gymnotiform fishes. J Physiol Paris. 2002 Sep-Dec;96(5-6):557-66.

Kopperud BT. Artiodactyl brain-size evolution. Department of Biosciences. Oslo: University of Oslo; 2017. 
Kotrschal A, Rogell B, Bundsen A, Svensson B, Zajitschek S, Brännström I, et al. Artificial selection on relative brain size in the guppy reveals costs and benefits of evolving a larger brain. Curr Biol. 2013 Jan;23(2):168-71.

Kotrschal K, Van Staaden MJ, Huber R. Fish brains: evolution and environmental relationships. Rev Fish Biol Fish. 1998;8(4):373-408.

Ksepka DT, Balanoff AM, Smith NA, Bever GS, Bhullar BS, Bourdon E, et al. Tempo and pattern of avian brain size evolution. Curr Biol. 2020 Jun;30(11):2026-2036.e3.

Lande R. Quantitative genetic analysis of multivariate evolution, applied to brain:body size allometry. Evolution.

1979 Mar;33(1Part2):402-16.

Lapicque L. Tableau général des poids somatique et encéphalique dans les espèces animales. Bull Mem Soc Anthropol Paris. 1907;8(1):24870.

Liao WB, Lou SL, Zeng Y, Kotrschal A. Large brains, small guts: the expensive tissue hypothesis supported within anurans. Am Nat. 2016 Dec;188(6):693-700.

Lüling K. Zur biologte und ökologte von Arapaima gigas (Pisces, Osteoglossidae). Zoomorphology. 1964;54(4):436-530.

Maeyama K, Nakayasu H. Postembryonic neurogenesis in zebrafish (Danio rerio) brain: presence of two different systems. Zool Sci. 2000;17(7):959-66.

Marhounová L, Kotrschal A, Kverková K, Kolm $\mathrm{N}$, Němec P. Artificial selection on brain size leads to matching changes in overall number of neurons. Evolution. 2019 Sep;73(9):200312.

Martin RD. Relative brain size and basal metabolic rate in terrestrial vertebrates. Nature. 1981 Sep;293(5827):57-60.

Merrick JR, Green LC. Pond culture of the spotted barramundi, Scleropages-Leichardti (Pisces, Osteoglossidae). Aquaculture. 1982;29(12):171-6.

Mitov V, Bartoszek K, Stadler T. Automatic generation of evolutionary hypotheses using mixed Gaussian phylogenetic models. Proc Natl Acad Sci USA. 2019 Aug;116(34):169216.

Montgomery SH, Mundy NI, Barton RA. Brain evolution and development: adaptation, allometry and constraint. Proc Biol Sci. 2016;283(1838):20160433.

Mull CG, Yopak KE, Dulvy NK. Does more maternal investment mean a larger brain? Evolutionary relationships between reproductive mode and brain size in chondrichthyans. Mar Freshw Res. 2011;62(6):567-75.

Mull CG, Yopak KE, Dulvy NK. Maternal investment, ecological lifestyle, and brain evolution in sharks and rays. Am Nat. 2020 Jun;195(6):1056-69.

Nguyen L, Paul C, Mamonekene V, Bartsch P, Tiedemann R, Kirschbaum F. Reproduction and development in some species of the weakly electric genus Campylomormyrus (Mormyridae, Teleostei). Environ Biol Fishes. 2017;100(1):49-68.
Nilsson G. Brain and body oxygen requirements of Gnathonemus petersii, a fish with an exceptionally large brain. J Exp Biol. 1996;199(Pt 3):603-7.

Oikawa S, Itazawa Y. Relative growth of organs and parts of the carp, Cyprinus-Carpio, with special reference to the metabolism-size relationship. Copeia. 1984;1984(3):800-3.

Oikawa S, Takemori M, Itazawa Y. Relative growth of organs and parts of a marine teleost, the porgy, Pagrus-major, with special reference to metabolism-size relationships. Jpn J Ichthyol. 1992;39(3):243-9.

Okedi J. A study of the fecundity of some mormyrid fishes from Lake Victoria. East Afr Agric For J. 1970;35(4):436-42.

Packard GC. On the use of logarithmic transformations in allometric analyses. J Theor Biol. 2009 Apr;257(3):515-8.

Pélabon C, Bolstad GH, Egset CK, Cheverud JM, Pavlicev M, Rosenqvist G. On the relationship between ontogenetic and static allometry. Am Nat. 2013 Feb;181(2):195-212.

Pennell MW, Eastman JM, Slater GJ, Brown JW, Uyeda JC, FitzJohn RG, et al. geiger v2.0: an expanded suite of methods for fitting macroevolutionary models to phylogenetic trees. Bioinformatics. 2014 Aug;30(15):2216-8.

$\mathrm{R}$ Core Team. R: A language and environment for statistical computing. 3.6.0 ed. Vienna, Austria: R Foundation for Statistical Computing; 2019.

Rabosky DL, Chang J, Title PO, Cowman PF, Sallan L, Friedman M, et al. An inverse latitudinal gradient in speciation rate for marine fishes. Nature. 2018 Jul;559(7714):392-5.

Radmilovich M, Barreiro I, Iribarne L, Grant K, Kirschbaum F, Castelló ME. Post-hatching brain morphogenesis and cell proliferation in the pulse-type mormyrid Mormyrus rume proboscirostris. J Physiol Paris. 2016 Oct;110(3 3 Pt B):245-58.

Rehkämper G, Frahm HD, Zilles K. Quantitative development of brain and brain structures in birds (galliformes and passeriformes) compared to that in mammals (insectivores and primates). Brain Behav Evol. 1991;37(3):12543.

Riedl R. A systems-analytical approach to macroevolutionary phenomena. Q Rev Biol. 1977 Dec;52(4):351-70.

Riska B, Atchley WR. Genetics of growth predict patterns of brain-size evolution. Science. 1985 Aug;229(4714):668-71

Riska B. Regression-models in evolutionary allometry. Am Nat. 1991;138(2):283-99.

Sacher GA, Staffeldt EF. Relation of gestation time to brain weight for placental mammals - Implications for theory of vertebrate growth. Am Nat. 1974;108(963):593-615.

Scott DB, Fuller JD. The reproductive biology of Scleropages formosus (Müller \& Schlegel) (Osteoglossomorpha, Osteoglossidae) in Malaya, and the morphology of its pituitary gland. J Fish Biol. 1976;8(1):45-53.
Silvestro D, Kostikova A, Litsios G, Pearman PB, Salamin N. Measurement errors should always be incorporated in phylogenetic comparative analysis. Methods Ecol Evol. 2015;6(3):340-6.

Simpson GG. Tempo and mode in evolution. Columbia University Press; 1944.

Smaers JB, Rothman RS, Hudson DR, Balanoff AM, Beatty B, Dechmann DK, et al. The evolution of mammalian brain size. Sci Adv. 2021 Apr;7(18):eabe2101.

Smith RJ. Use and misuse of the reduced major axis for line-fitting. Am J Phys Anthropol. 2009 Nov;140(3):476-86.

Stephan H, Frahm H, Baron G. New and revised data on volumes of brain structures in insectivores and primates. Folia Primatol (Basel). 1981;35(1):1-29.

Striedter GF. Principles of brain evolution. Sinauer Associates; 2005

Sukhum KV, Freiler MK, Carlson BA. Intraspecific energetic trade-offs and costs of encephalization vary from interspecific relationships in three species of mormyrid electric fishes. Brain Behav Evol. 2019;93(4):196-205.

Sukhum KV, Freiler MK, Wang R, Carlson BA. The costs of a big brain: extreme encephalization results in higher energetic demand and reduced hypoxia tolerance in weakly electric African fishes. Proc Biol Sci. 2016 Dec;283(1845):283.

Sukhum KV, Shen J, Carlson BA. Extreme enlargement of the cerebellum in a clade of teleost fishes that evolved a novel active sensory system. Curr Biol. 2018 Dec;28(23):38573863.e3.

Sylvester JB, Rich CA, Loh YH, van Staaden MJ, Fraser GJ, Streelman JT. Brain diversity evolves via differences in patterning. Proc Natl Acad Sci USA. 2010 May;107(21):971823.

Tomoda H, Uematsu K. Morphogenesis of the brain in larval and juvenile Japanese eels, Anguilla japonica. Brain Behav Evol. 1996;47(1):33-41.

Toyoda J, Uematsu K. Brain morphogenesis of the red sea bream, Pagrus major (teleostei). Brain Behav Evol. 1994;44(6):324-37.

Tsuboi M, Husby A, Kotrschal A, Hayward A Buechel SD, Zidar J, et al. Comparative support for the expensive tissue hypothesis: big brains are correlated with smaller gut and greater parental investment in Lake Tanganyika cichlids. Evolution. 2015 Jan;69(1):190 200

Tsuboi M, Kotrschal A, Hayward A, Buechel SD, Zidar J, Løvlie H, et al. Evolution of brainbody allometry in Lake Tanganyika cichlids. Evolution. 2016 Jul;70(7):1559-68.

Tsuboi M, Lim AC, Ooi BL, Yip MY, Chong VC, Ahnesjö I, et al. Brain size evolution in pipefishes and seahorses: the role of feeding ecology, life history and sexual selection. J Evol Biol. 2017 Jan;30(1):150-60. 
Tsuboi M, van der Bijl W, Kopperud BT, Erritzoe J, Voje KL, Kotrschal A, et al. Brain mass and body mass datasets and phylogenies linked to brain-body allometry and the encephalization of birds and mammals. figshare. 2018a. https://doi.org/https://doi.org/10.6084/ m9.figshare.6803276.v1.

Tsuboi M, van der Bijl W, Kopperud BT, Erritzøe J, Voje KL, Kotrschal A, et al. Breakdown of brain-body allometry and the encephalization of birds and mammals. Nat Ecol Evol. 2018b Sep;2(9):1492-500.

Uyeda JC, Harmon LJ. A novel Bayesian method for inferring and interpreting the dynamics of adaptive landscapes from phylogenetic comparative data. Syst Biol. 2014 Nov;63(6):90218.

Uyeda JC, Pennell MW, Miller ET, Maia R, McClain CR. The evolution of energetic scaling across the vertebrate tree of life. Am Nat. 2017 Aug;190(2):185-99.
Verba JT, Rabello Neto JG, Zuanon J, Farias I. Evidence of multiple paternity and cooperative parental care in the so called monogamous silver arowana Osteoglossum bicirrhosum (Osteoglossiformes: osteoglossidae). Neotrop Ichthyol. 2014;12(1):145-51.

Voje KL, Hansen TF, Egset CK, Bolstad GH, Pélabon C. Allometric constraints and the evolution of allometry. Evolution. 2014 Mar;68(3):866-85.

Von der Emde G, Bleckmann H. Finding food: senses involved in foraging for insect larvae in the electric fish gnathonemus petersii. J Exp Biol. 1998 Apr;201(Pt 7):969-80.

White JF, Gould SJ. Interpretation of the coefficient in the allometric equation. Am Nat. 1965;99(904):5-18.
Workman AD, Charvet CJ, Clancy B, Darlington RB, Finlay BL. Modeling transformations of neurodevelopmental sequences across mammalian species. J Neurosci. 2013 Apr;33(17):7368-83.

Wullimann MF, Puelles L. Postembryonic neural proliferation in the zebrafish forebrain and its relationship to prosomeric domains. Anat Embryol (Berl). 1999 Apr;199(4):329-48.

Yopak KE, Lisney TJ, Darlington RB, Collin SP, Montgomery JC, Finlay BL. A conserved pattern of brain scaling from sharks to primates. Proc Natl Acad Sci USA. 2010 Jul;107(29):12946-51.

Yue GH, Chang A, Yuzer A, Suwanto A. Current knowledge on the biology and aquaculture of the endangered Asian arowana. Rev Fish Sci Aquacult. 2020;28(2):193-210. 